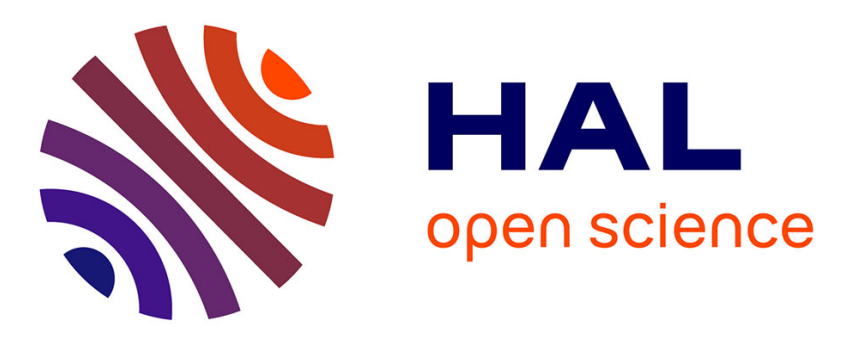

\title{
Relative age determination of Rattus tiomanicus using allometric measurements
}

\author{
Aude Verwilghen, Marie-Agnès Rabillard, Yannick Chaval, Dominique Rieffel, \\ Martua Hasiholan Sinaga, Mohd Naim, Jean-Pierre Caliman, Patrick \\ Giraudoux, Francis Raoul
}

\section{To cite this version:}

Aude Verwilghen, Marie-Agnès Rabillard, Yannick Chaval, Dominique Rieffel, Martua Hasiholan Sinaga, et al.. Relative age determination of Rattus tiomanicus using allometric measurements. Mammalia, 2015, 79 (1), pp.81-90. 10.1515/mammalia-2013-0113 . hal-01114386

\author{
HAL Id: hal-01114386 \\ https://hal.science/hal-01114386
}

Submitted on 27 May 2020

HAL is a multi-disciplinary open access archive for the deposit and dissemination of scientific research documents, whether they are published or not. The documents may come from teaching and research institutions in France or abroad, or from public or private research centers.
L'archive ouverte pluridisciplinaire HAL, est destinée au dépôt et à la diffusion de documents scientifiques de niveau recherche, publiés ou non, émanant des établissements d'enseignement et de recherche français ou étrangers, des laboratoires publics ou privés. 


\section{Relative age determination of Rattus tiomanicus using allometric measurements}

\begin{abstract}
For sustainable oil palm production, barn owl (Tyto alba) predation should be enhanced and monitored to better understand its impact on rodent population dynamics, notably for selective predation based on age or size. Our aim was to assess the best combination of osteometric variables that predict eye lens weight and thus the relative age of an individual Rattus tiomanicus based on pellet remains. We captured 161 individuals in an oil palm plantation in Indonesia and measured 15 osteometric variables for the jaw, skull, and femur. We investigated the variables' correlations with eye lens weight and estimated the measurement errors. In addition, 120 pellets were collected to assess the frequency of different types of bones. Predictive modelling was then used. We suggest that the model using the femur length would be more appropriate, even if it is slightly less precise than the models that consider the skull and jaw variables. The femur was well represented in the pellet sample, its length highly correlated with the eye lens weight, with a low measurement error. Our study demonstrates the utility of femur length for age prediction in prey from macroremains in oil palm plantations, wherein most pellets are headless and R. tiomanicus is the dominant prey.
\end{abstract}

Keywords: allometry; barn owl pellet; eye lens weight; oil palm plantation; rodent.

\footnotetext{
*Corresponding author: Aude Verwilghen, CIRAD, UPR Systèmes de pérennes, TA B-34/02, Avenue Agropolis, F-34398 Montpellier, France; and Department of Chrono-environment, UMR UFC/CNRS 6249 aff. INRA, University of Franche-Comté, Place Leclerc, 25030 Besançon cedex, France, e-mail: aude.verwilghen@cirad.fr Marie-Agnès Rabillard: CIRAD, UPR Systèmes de pérennes, TA B-34/02, Avenue Agropolis, F-34398 Montpellier, France Yannick Chaval: INRA, UMR CBGP (INRA/IRD/Cirad/Montpellier SupAgro), Campus International de Baillarguet, CS 30016, 34988 Montferrier-sur-Lez cedex, France

Dominique Rieffel and Francis Raoul: Department of Chronoenvironment, UMR UFC/CNRS 6249 aff. INRA, University of FrancheComté, Place Leclerc, 25030 Besançon cedex, France

Martua Hasiholan Sinaga: LIPI, Research Center for Biology, Jl. Raya Jakarta-Bogor Km. 46, Cibinong 16911, Indonesia
}

Mohd Naim: SMART Research Institute, P.T. Smart Tbk., Jalan Teuku Umar, No. 19, Pekanbaru 28112, Riau, Indonesia Jean-Pierre Caliman: CIRAD, UPR Systèmes de pérennes, TA B-34/02, Avenue Agropolis, F-34398 Montpellier, France; and SMART Research Institute, P.T. Smart Tbk., Jalan Teuku Umar, No. 19, Pekanbaru 28112, Riau, Indonesia Patrick Giraudoux: Department of Chrono-environment, UMR UFC/ CNRS 6249 aff. INRA, University of Franche-Comté, Place Leclerc, 25030 Besançon cedex, France; and Institut Universitaire de France, 103 Boulevard Saint-Michel, 75005 Paris, France

\section{Introduction}

Oil palm is one of the world's most rapidly expanding crops; the main producer countries are Indonesia and Malaysia (Oil World 2012). Expanding oil palm plantations (OPPs) over large areas support rodent population outbreaks, and certain rodents are considered invasive pests that cause significant damage to production (Liau 1990, Turner and Gillbanks 2003). Pest control typically includes treating a field using anticoagulant rodenticides and/or reinforcing barn owl predation (Tyto alba, Scopoli) in the plantation by providing nest boxes (Wood and Fee 2003). For more sustainable oil palm production, natural predation by barn owls should be enhanced, which requires that we better understand its impact on rodent population dynamics (Hafidzi 1994), notably for selective predation based on rodent age or size (Saint Girons 1973, Kittlein 1997).

In Southeast Asian OPPs, barn owls primarily feed on rats (Lenton 1984, Small 1990, Puan et al. 2011); their prey spectrum is almost entirely confined to the three species, which are the major pests for oil palm crop: Rattus tiomanicus Miller, the Malaysian field rat; Rattus argentiventer Robinson and Kloss, the ricefield rat; and Rattus tanezumi Temminck (synonym: Rattus rattus diardii Jentink), the oriental house rat (Liau et al. 1993, Corley and Tinker 2003, Wood and Fee 2003). In most mature estates, R. tiomanicus predominates (Hafidzi and Saayon 2001, Wood and Fee 2003, Chia 2005), wherein it composes most of the barn owl prey (Lenton 1984). Although barn owl predation on 
rats on oil palm estates is widely used and has been primarily studied in Malaysia for a long time (Duckett 1976, 2008, Lenton 1980, Small 1990), the real effect of barn owl predation on the rat population is inconclusive (Chia et al. 1995, Wood and Fee 2003). In addition, there is no clear pattern for selective predation based on size, weight, or age (Small 1990, Lim et al. 1993, Hafidzi and Naim 2003, Puan et al. 2011), and certain authors suggest that differential barn owl predation may be site specific (Trejo and Guthmann 2003, Leveau et al. 2006). Therefore, predation must be locally investigated to adapt pest control strategies to each plantation/site.

Thus, as suggested by Sherfy et al. (2006), prediction models based on morphometrics are valuable for reconstructing the prey population age structure, which is a useful tool for monitoring the demographic consequences of population control. Eye lens weight (ELW) is considered to be the most accurate age indicator for mammals because it varies much less with environmental conditions than other body measurements (Lord 1959, Friend 1967, Morris 1972, Pucek and Lowe 1975, Leirs 1994, Gliwicz and Jancewicz 2001, Lalis et al. 2006, Augusteyn 2008). ELW is widely used to estimate rodents' exact or relative age (Le Louarn 1971, Poulet 1980, Barnett and Dutton 1995, Burlet et al. 2010). Eye lens growth patterns from known-age individuals bred in a laboratory have primarily been investigated using vole and mice (Rowe et al. 1985, Yabe and Arakawa 2009). A few Rattus species also exhibit a quantitative relationship between age and ELW (Williams 1976, Hardy et al. 1983, Tanikawa 1993, Shrestha et al. 2002); however, Rattus tiomanicus has not been studied. The eye lens cannot be retrieved from raptor pellets; however, other macroremains can be collected, such as skulls and bones. Therefore, models have been developed to predict the ELW from osteometric measurements. Variables related to skull and jaw dimensions are typically considered most appropriate for small-mammal age estimations using macroremains (Quéré et al. 1994, Granjon and Traoré 2007). However, because of prey decapitation, the absence of skull was frequently reported for barn owl pellets from Southeast Asian OPPs (Medway and Yong 1970 in Lenton 1984, Lim et al. 1993, Hafidzi and Naim 2003, Puan et al. 2011); thus, it was necessary to use variables other than cranial and dental variables. Very few authors have investigated the allometric relationships between osteometric measurements and age or size/body weight for R. tiomanicus (Small 1990, Lim et al. 1991, 1993), although this species is the most studied rodent pest in OPPs (Wood 1984, Wood and Liau 1984a,b, Buckle et al. 1997, Chia 2005). Moreover, only two authors, Lim et al. (1993) and Puan et al. (2011), have explored the relationship between femur length and relative age, respectively, for $R$. tiomanicus and Rattus tanezumi, to overcome the absence of skull elements in pellets.

In this study, we investigated the correlations between ELW and a range of osteometric measurements for Rattus tiomanicus trapped in a Sumatran (Indonesia) OPP. Our objectives were to assess the following: (i) the frequency of different types of bones and their physical integrity in barn owl pellets and (ii) the best combination of osteometric variables to predict $R$. tiomanicus lens weights theoretically (i.e., considering all variables) and practically (i.e., considering the bones most often observed in owl pellets).

\section{Materials and methods}

\section{Study site and sampling design}

The research was conducted at the Libo Estate, which is a large-scale OPP (approximately $4370 \mathrm{ha}$ ) in the Riau Province, Sumatra. The climate is typically humid equatorial, with an average temperature of $28^{\circ} \mathrm{C}$, a mean annual rainfall of $2500 \mathrm{~mm}$, and two dry seasons in February and June through August. The palm plantation is old (it was planted between 1986 and 1990) and has not been treated using rodenticide for $>10$ years after the introduction of barn owls for rodent pest control in the 1990s. The rodents were trapped in May 2011. Nine trap lines with 25 cage traps were set up approximately every $9 \mathrm{~m}$ at the base of palm trees. The traps were set for two or three consecutive nights (seven trap lines were only set for two consecutive nights) and controlled each morning. We used locally constructed cage traps $(32 \times 12 \times 15 \mathrm{~cm})$ that were baited with freshly cut half of a palm fruit. The traps were located in the plantation core at a minimum distance of $600 \mathrm{~m}$ from human settlements to minimise trapping species other than Rattus tiomanicus.

\section{Species identification and osteometric measurements}

The rats were euthanised using chloroform (outdoors with safety precautions for the operator's health) and then sexed, and classic external body measurements were collected (weight, head/body, and tail length; see Herbreteau et al. 2011). The head and left leg were severed for further dissection, boiled in an autoclave at $121^{\circ} \mathrm{C}$ for $30 \mathrm{~min}$, and then submerged in water for 1 week to ease bone and flesh separation. For eye lens processing, various similar 
techniques are described in the literature (Poulet 1980, Rowe et al. 1985, Shrestha et al. 2002, Jánová et al. 2007), and as noted by Lalis et al. (2006), the accuracy is rarely assessed. We adapted the protocol to tropical conditions. The eyeballs were removed and fixed in $4 \%$ formalin for at least 2 weeks in a refrigerator. The lenses were then excised, washed with distilled water, and oven dried at $40^{\circ} \mathrm{C}$ in two batches for 9 and 7 days (given the humid conditions, a preliminary trial was used for the first batch to estimate the drying duration necessary for weight stabilisation). Once out of the oven, the eyeballs were immediately weighed in pairs to the nearest $0.1 \mathrm{mg}$. The mean weight of each pair was used for analysis.

One hundred and sixty-one presumably Rattus tiomanicus individuals (identified according to external morphology; Corbett and Hill 1992, Aplin et al. 2003) were used as the reference collection for our measurements. A subsample composed of 120 individuals was selected using the following process. A principal component analysis with log-transformed osteometric measurements (see below) was used to select three variables that were least correlated between each other and least correlated for animal size (BP, CML1-3, and JawL1; see Figure 1). The

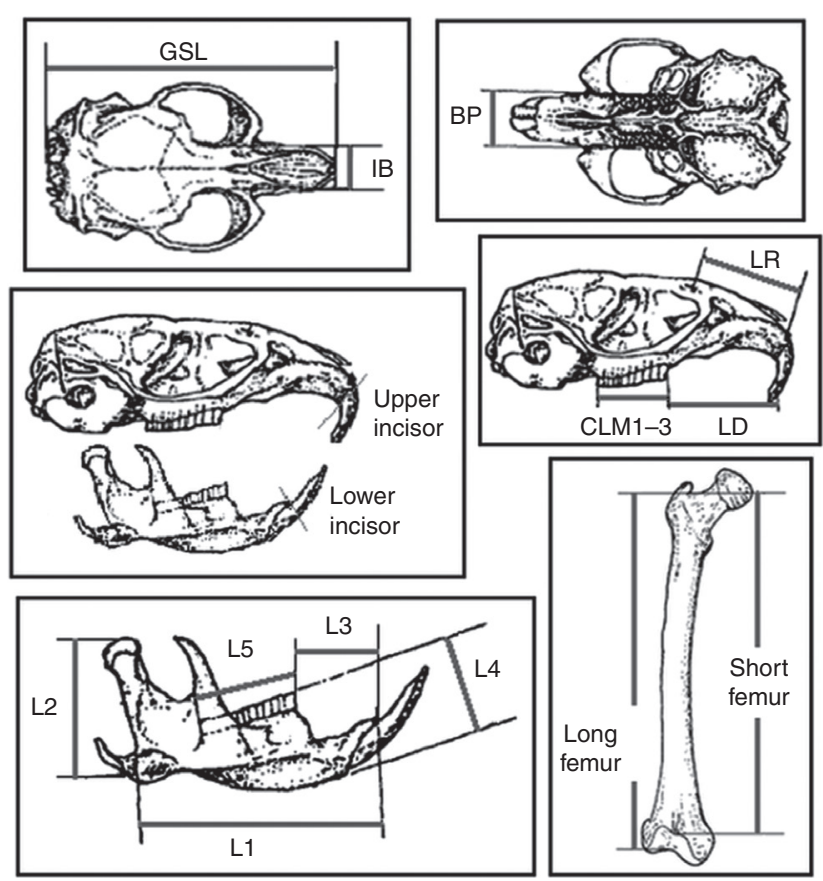

Figure 1 Skull, jaw, and femur variables. Adapted from Quéré et al. (1994).

Skull: GSL, greater skull length; IB, interorbital breadth; LR, length of rostrum; CLM1-3, molar row length; LD, length of diastema; BP, breadth of palate; and upper incisors. Jaw: L1, mandible length; L2, mandible height; L3, diastema height; L4, jaw height; L5, molar row length; and lower incisor. Femur, short femur and long femur. animals were then selected at the periphery and centre of the data cloud from a triangular graph, wherein the axes were the three variables. The animals were then identified using a molecular barcoding method, with species assignation using the RodentSEA reference database available at http://www.ceropath.org/barcoding_tool/rodentsea (Clairon et al. 2010).

The following 15 osteometric variables (Figure 1) were measured to the nearest $0.1 \mathrm{~mm}$ for each specimen by the same person using digital calipers: (i) in accordance with Dickman et al. (1991) and Quéré et al. (1994), 11 variables for the skull and jaw that relate well to age and are typically collected intact from bones and easily found in pellets; (ii) two femur variables, one composing the entire length of the bone, and the other excluding the distal epiphysis cartilage that is often absent (hereafter, the "short length"); the femur was used because certain authors note that heads are frequently absent from the pellets in OPPs, likely because barn owls decapitate their prey before carrying them to the nest (Lenton 1984, Lim et al. 1991); and (iii) two incisor variables were measured to use small-carnivore scat in the model because incisors are typically the only intact rat remnant in a scat (Bonnaud et al. 2008).

Material used for measurement (skull, femur, and eye lenses of each of the 161 specimens) is available at the Centre de cooperation internationale en recherche agronomique pour le développement (CIRAD), Montpellier, France. Specimens are labelled LI1105XXxx (xx being the number of the individual trapped on the line XX; traplines are labelled AA, AB, AC, AD, AE, AR, AS, AT, AU).

The final aim of this study was to propose a model with a combination of variables (osteometric measurements) that best predicts the ELW and thus the relative rat age based on pellet remains. Therefore, concurrent with trapping, we collected the intact barn owl pellets inside nest boxes in our study area and the vicinity. One hundred pellets were collected in 57 nest boxes, covering an area of approximately 1600 ha (typically, one nest box in each block of $30 \mathrm{ha}$ ). It has been suggested that the presence or absence of skulls in pellets is associated with an owl's breeding cycle (Lenton 1984, Hafidzi and Naim 2003). Subsequently, 20 additional pellets were retrieved in August 2010, during the barn owl breeding peak, to encompass a potential behavioural change in prey consumption. We examined the occurrence and integrity of the rodent skull, jaw, and femur in pellets to assess which of the 15 variables were most likely to be collected from the pellets. We also estimated the imprecision for measurements from the same observer over two measurement sessions; the 15 variables from a sample composed of 30 rats were measured twice by the same person. 


\section{Statistical analysis}

The percentage of measurement error (\%ME; i.e., the percentage of sample variation due to measurer imprecision) can be defined as "the ratio of the within-measurement component of variance to the sum of the within- and among-measurement component" (Bailey and Byrnes 1990):

$$
\% \mathrm{ME}=\left[\mathrm{s}_{\text {within }}{ } /\left(\mathrm{s}_{\text {within }}^{2}+\mathrm{s}^{2} \text { among }\right)\right] \times 100 .
$$

The mean squares of the one-way ANOVA were calculated to determine the components of variance:

$$
\mathrm{s}_{\text {within }}^{2}=\mathrm{MSS}_{\text {within }}
$$

and

$$
\mathrm{S}_{\text {among }}^{2}=\left(\mathrm{MSS}_{\text {among }}-\mathrm{MSS}_{\text {within }}\right) / \mathrm{m} \text {, }
$$

where $\mathrm{m}$ is the number of repeated measurements (Yezeriniac et al. 1992, Claude 2008).

Two sets of models were computed based on two sets of variables: (i) all osteometric variables without considering whether they can be frequently collected from the pellets ("theoretical" model) and (ii) variables most commonly found in pellets due to high bone integrity (i.e., likely to be most useful for researchers and practitioners working with pellets; "practical" models). The practical models were constructed using the osteometric variables selected on the basis of three criteria: (i) the frequency in pellets is $>10 \%$; (ii) the Pearson correlation coefficient for the given variable with an ELW is $\geq 0.8$; and (iii) the ME percentage is $<10 \%$. Because we did not have a biological a priori for the order of variables in the model, a stepwise procedure (backward and forward) was used to select the best set of predictors based on the Akaike information criterion (AIC) (Burnham and Anderson 2002). Visual analyses of bivariate graphs among the ELW and osteometric measurements suggested that linear modelling was an acceptable option. The normality of model residuals was determined using the Kolmogorov-Smirnov goodness of fit test. We used a 10-fold cross-validation procedure to estimate the coefficient of determination $\left(\mathrm{R}^{2}\right)$ and the root mean squared error (Rmse), which is a good measure of model fit and accuracy.

The prey's sex cannot be defined in pellets using our measurements. However, we investigated a potential difference in ELW between sexes from our trapped sample using a linear model. In addition, we also investigated the performance of models, including the variable sex as a covariate, to assess whether a bias was induced by using only one equation for both sexes.

The data were statistically analysed using the $R$ software (version 2.15.0; R Foundation for Statistical
Computing, Vienna, Austria) and the packages ade4, bootstrap, DAAG, epicalc, lattice, pgirmess, plotrix, and ipred.

\section{Results}

\section{Rattus tiomanicus characteristics}

Among the 120 individuals that were subsampled for molecular identification, 110 were successfully sequenced, $100 \%$ of which were confirmed as Rattus tiomanicus. Summary statistics on the body and bone measurements (Table 1) as well as ELW distribution (Figure 2) suggest that both juvenile and adult specimens were sampled with minimum and maximum body weights at 17 and $139 \mathrm{~g}$, respectively. The sex ratio of our sample was 1.36 males per female. We did not detect a significant difference in ELW between males and females (F-value $=0.0723, p=0.7883$; Kolmogorov-Smirnov test of

\begin{tabular}{|c|c|c|c|}
\hline Variable & $\begin{array}{r}\text { Mean } \pm \text { standard } \\
\text { deviation }\end{array}$ & Minimum & Maximum \\
\hline Body weight (g) & $72.73 \pm 23.27$ & 17.00 & 139.00 \\
\hline Body length (mm) & $139.9 \pm 15.1$ & 90.00 & 183.00 \\
\hline Tail length (mm) & $144.4 \pm 14.6$ & 85.00 & 189.00 \\
\hline $\begin{array}{l}\text { Eye lens weight } \\
(\mathrm{mg}) \\
\text { Jaw }(\mathrm{mm})\end{array}$ & $35.98 \pm 7.02$ & 13.20 & 64.00 \\
\hline L1 & $16.82 \pm 1.24$ & 11.77 & 21.02 \\
\hline L2 & $8.97 \pm 0.97$ & 4.77 & 12.18 \\
\hline L3 & $5.27 \pm 0.43$ & 3.51 & 7.08 \\
\hline L4 & $5.19 \pm 0.55$ & 3.21 & 7.52 \\
\hline $\mathrm{L} 5$ & $6.16 \pm 0.15$ & 4.23 & 6.86 \\
\hline Lower incisor & $1.62 \pm 0.20$ & 0.87 & 2.35 \\
\hline \multicolumn{4}{|l|}{ Skull (mm) } \\
\hline GSL & $36.27 \pm 2.62$ & 25.67 & 41.92 \\
\hline IB & $5.68 \pm 0.45$ & 4.30 & 7.10 \\
\hline LR & $12.74 \pm 1.24$ & 8.21 & 17.30 \\
\hline CLM1-3 & $6.40 \pm 0.19$ & 5.21 & 7.12 \\
\hline LD & $9.87 \pm 1.01$ & 6.51 & 12.92 \\
\hline $\mathrm{BP}$ & $4.49 \pm 0.40$ & 2.60 & 6.49 \\
\hline Upper incisor & $1.97 \pm 0.20$ & 1.18 & 2.71 \\
\hline \multicolumn{4}{|l|}{ Femur (mm) } \\
\hline Long femur & $23.57 \pm 3.00$ & 12.62 & 30.40 \\
\hline Short femur & $20.20 \pm 2.63$ & 10.97 & 26.45 \\
\hline
\end{tabular}

Table 1 Summary statistics for Rattus tiomanicus body and bone measurements $(n=161)$.

L1, mandible length; L2, mandible height; L3, diastema length; L4, jaw height; L5, molar row length; GSL, greater skull length; IB, interorbital breadth; LR, length of rostrum; CLM1-3, molar row length; $L D$, length of diastema; and BP, breadth of palate. 


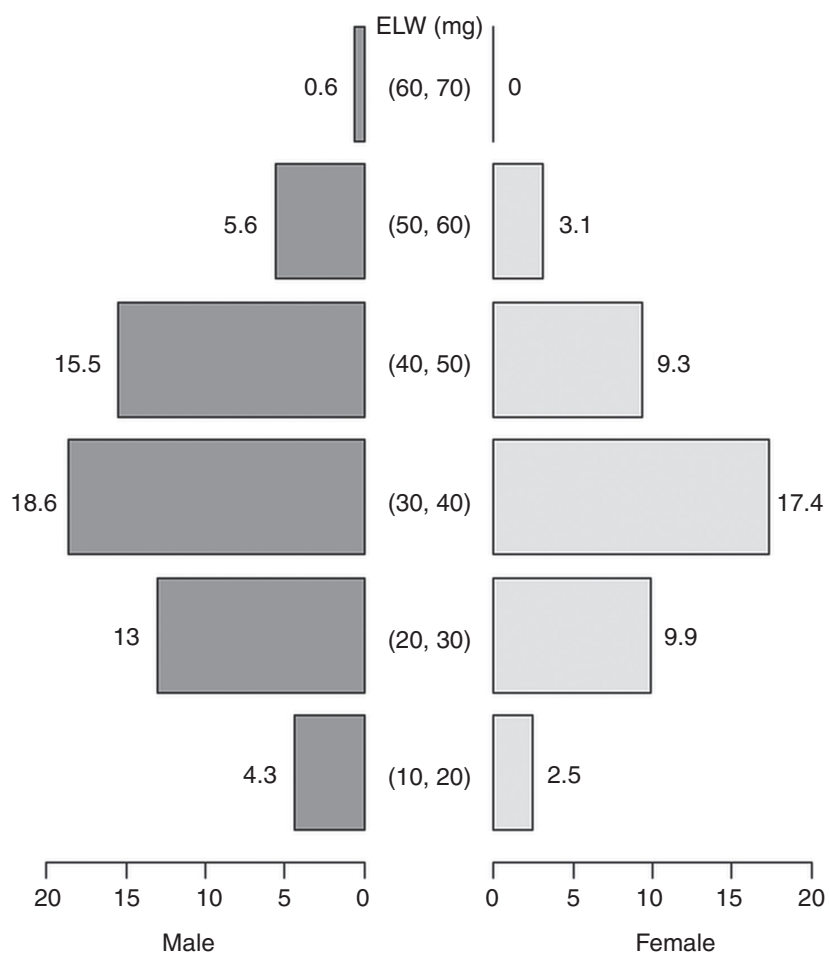

Figure 2 Population eye lens weight pyramid-stratified using sex for a Rattus tiomanicus sample $(\mathrm{n}=161)$ trapped on an oil palm plantation in Riau (Indonesia).

The numbers at the bar tops are percentages of the total.

residuals normality: $p=0.9747$; Bartlett test of homogeneity of residuals variance: $\mathrm{p}=0.2532$ ).

\section{Bone frequency in pellets and measurement errors}

As reported in Table 2, full osteometric measurements were impossible in at least $70 \%$ of pellets because of the low integrity of the skull and jaw bones in barn owl pellets. However, we measured the short femur in $80.8 \%$ of pellets. Between the two different sessions of measurements (by the same person), the percentage of measurement errors was low for the short femur $(\% \mathrm{ME}=0.23)$. The L1 and L2 values were also among the lowest at 1.8\% and $1.4 \%$, respectively. Seven variables, L3, L4, L5, Lower incisor, IB, CLM1-3, and Upper incisor, were $>10 \%$ ME.

\section{Predictive models for the relative age estimation}

The Pearson correlation coefficients ( $\mathrm{r}$ ) between the ELW and the variables CLM1-3 and L5 were $<0.4$ (Table 2).
Table 2 Frequency in barn owl pellets $(n=120)$, measurement errors, and correlation with eye lens weight for each Rattus tiomanicus osteometric variable $(n=161)$.

\begin{tabular}{|c|c|c|c|c|}
\hline \multirow[t]{2}{*}{$\begin{array}{l}\text { Osteometric } \\
\text { variable }\end{array}$} & \multirow[t]{2}{*}{$\begin{array}{r}\text { Frequency in } \\
\text { pellets (\%) }\end{array}$} & \multirow[t]{2}{*}{$\begin{array}{r}\text { Measurement } \\
\text { error (\%) }\end{array}$} & \multicolumn{2}{|c|}{$\begin{array}{l}\text { Correlation with } \\
\text { eye lens weight }\end{array}$} \\
\hline & & & $\begin{array}{r}\text { Pearson } \\
\text { coef. } r\end{array}$ & p-Value \\
\hline \multicolumn{5}{|l|}{ Jaw } \\
\hline 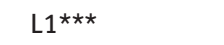 & $30.0 *$ & $1.8^{\star}$ & $0.85^{\star}$ & $<0.001$ \\
\hline $\mathrm{L} 2^{\star \star \star}$ & $30.8^{*}$ & $1.4^{\star}$ & $0.89 *$ & $<0.001$ \\
\hline L3 & $32.5^{\star}$ & 11 & $0.83^{*}$ & $<0.001$ \\
\hline L4 & $32.5^{\star}$ & 10.8 & $0.87^{\star}$ & $<0.001$ \\
\hline L5 & $32.5^{\star}$ & 10.6 & 0.37 & $<0.001$ \\
\hline Lower incisor & $32.5^{\star}$ & 14.5 & $0.86^{*}$ & $<0.001$ \\
\hline \multicolumn{5}{|l|}{ Skull } \\
\hline GSL & 2.5 & $0.2^{\star}$ & $0.87^{*}$ & $<0.001$ \\
\hline IB & $21.7^{*}$ & 26.4 & $0.79 *$ & $<0.001$ \\
\hline LR & 8.3 & $4.9^{\star}$ & $0.89 *$ & $<0.001$ \\
\hline CLM1-3 & $25.8^{\star}$ & 26.8 & 0.27 & $<0.001$ \\
\hline $\mathrm{LD}^{\star \star \star}$ & $23.3^{*}$ & $1.9^{*}$ & $0.86^{*}$ & $<0.001$ \\
\hline $\mathrm{BP} \star \star \star$ & $23.3^{\star}$ & $4^{\star}$ & $0.83^{*}$ & $<0.001$ \\
\hline Upper incisor & $22.5^{\star}$ & 12.7 & $0.83^{*}$ & $<0.001$ \\
\hline \multicolumn{5}{|l|}{ Femur } \\
\hline Long femur*** & $25.0^{\star}$ & $1.2^{\star}$ & $0.92^{\star}$ & $<0.001$ \\
\hline Short femur & $80.8^{\star}$ & $0.2^{\star}$ & $0.92^{*}$ & $<0.001$ \\
\hline
\end{tabular}

L1, mandible length; L2, mandible height; L3, diastema length; L4, jaw height; L5, molar row length; GSL, greater skull length; IB, interorbital breadth; LR, length of rostrum; CLM1-3, molar row length; $L D$, length of diastema; and BP, breadth of palate. The values that fit with the pre-selection criteria (see Material and methods) are marked with an asterisk; the variables pre-selected for "practical" predictive modelling are indicated with three asterisks.

Other variables were strongly correlated with lens weight; $\mathrm{r}$ ranged from 0.79 to 0.92 , and the most correlated variables were the short and long femur. Using criteria based on frequency in pellets $(>10 \%)$, the measurement errors $(<10 \%)$ and correlation with lens weight $(r \geq 0.8)$, only six variables, namely, L1, L2, LD, and BP, as well as the short and long femur, were selected for the first predictive model (see Table 2). The model that best predicted the ELW was the model that included L2, LD, BP, and the short femur with an $\mathrm{AIC}=435.62$ and $\mathrm{R}^{2}=0.847$ (model 1, Table 3). Because most pellets are headless, we investigated a model based on the short femur measurement only; the AIC for this model (model 2, Table 3) was greater than model 1 (458.04 vs. 435.62). The accuracy evaluation for the two "practical" models through cross validation showed that model 1 was slightly more accurate at estimating ELW than the model that only included the femur (Rmse=3.86 vs. Rmse=4.14, only considering the femur). A "theoretical" model was constructed on 
Table 3 Comparison of predictive model fitness and accuracy for Rattus tiomanicus eye lens weight estimation using a stepwise procedure and cross validation.

\begin{tabular}{|c|c|c|c|c|c|}
\hline Pre-selection of variables & Model & $\begin{array}{l}\text { Best combination of variables and associated } \\
\text { equation }\end{array}$ & AIC & $\mathbf{R}^{2}$ & Rmse \\
\hline L1, L2, LD, BP, short and long femur & 1 & $\begin{array}{l}E L W=(1.5060 L 2+0.8413 L D+2.7511 B P+1.4777 \\
\text { Short femur)-28.0396 }\end{array}$ & 435.62 & 0.847 & 3.86 \\
\hline L1, L2, LD, BP, short and long femur, sex & 1 sex & $\begin{array}{l}E L W=(-1.542 \text { Sex+1.601 L2+0.909 LD+2.560 } \\
B P+1.276 \text { Long femur) }-28.278\end{array}$ & 431 & 0.851 & 3.83 \\
\hline Short femur & 2 & $E L W=(2.806$ Short femur) -20.705 & 458.04 & 0.859 & 4.14 \\
\hline Short femur, sex & $2 \operatorname{sex}$ & $E L W=(-1.186$ Sex+2.813 Short femur) -20.3405 & 456.72 & 0.851 & 4.16 \\
\hline All variables & 3 & $\begin{array}{l}E L W=(0.8263 \mathrm{~L} 2-2.4834 \mathrm{~L} 5+0.7125 \mathrm{LD}+2.6186 \\
\mathrm{BP}+4.4933 \text { Upper incisor+5.5058 Lower } \\
\text { incisor+1.2114 Short femur) }-17.1739\end{array}$ & 422.05 & 0.865 & 3.78 \\
\hline All variables, including sex & $3 \operatorname{sex}$ & $\begin{array}{l}E L W=(-1.260 \mathrm{Sex}+1.101 \mathrm{~L} 2-1.603 \mathrm{~L} 3-2.425 \\
\mathrm{L} 5+1.030 \mathrm{LD}+2.502 \mathrm{BP}+4.146 \text { Upper incisor }+6.126 \\
\text { Lower incisor+1.245 Short femur)-14.637 }\end{array}$ & 419.1 & 0.851 & 3.71 \\
\hline
\end{tabular}

Models 1 and 2 are "practical" models, and model 3 is the "theoretical" model.

ELW, eye lens weight; L1, mandible length; L2, mandible height; L3, diastema length; L5, molar row length; LD, length of diastema; and $\mathrm{BP}$, breadth of palate.

the basis of all of the jaw, skull, and femur variables. The seven-variable combination that best predicted the ELW is shown in Table 3 (model 3). This model performed better than both of the best "practical" models (AIC $=422.05$ and $\mathrm{R}^{2}=0.865$ ); however, we only detected a slight improvement in the prediction precision (Rmse=3.78). The standard errors for the parameter estimates in the three models are presented in Table 4. Including the variable sex as a covariate slightly improved the performance of the models

Table 4 Parameter estimates and associated standard error (SE) for the Rattus tiomanicus eye lens weight prediction models.

\begin{tabular}{lrr}
\hline Variable & Estimate & SE \\
\hline Model 1 & & \\
Constant & -28.0396 & 2.4500 \\
L2 & 1.5060 & 0.5760 \\
LD & 0.8413 & 0.5351 \\
BP & 2.7511 & 0.9358 \\
Short femur & 1.4777 & 0.2697 \\
Model 2 & & \\
Constant & -20.705 & 1.9790 \\
Short femur & 2.806 & 0.0966 \\
Model 3 & & \\
Constant & -17.1739 & 6.6529 \\
L2 & 0.8263 & 0.5763 \\
L5 & -2.4834 & 1.1539 \\
LD & 0.7125 & 0.5094 \\
BP & 2.6186 & 0.8939 \\
Upper incisor & 4.4933 & 2.3100 \\
Lower incisor & 5.5058 & 2.3749 \\
Short femur & 1.2114 & 0.2710 \\
\hline
\end{tabular}

L1, mandible length; L2, mandible height; L3, diastema length; L5, molar row length; LD, length of diastema; and BP, breadth of palate. (models 1sex, 2sex, and 3sex; Table 3). Our assumptions on the homogeneity of variance, independence, linearity, and normality of error were examined for each model. The normality of residuals was confirmed for each model (Kolmogorov-Smirnov test, $\mathrm{p}=0.843$ for model 3, $\mathrm{p}=0.426$ for model 1 , and $\mathrm{p}=0.331$ for model 2 ).

\section{Discussion}

We presented a set of best equations for the prediction of Rattus tiomanicus' ELW, based on various skull, jaw, and femur measurements. We demonstrate here that, because rodent heads are frequently absent from barn owl pellets in Malaysian and Indonesian OPPs, the predictive model based only on the femur was the most useful, although slightly less precise than the models based on skull and jaw variables. We also argue that we can confidently attribute most, if not all, femurs in the pellets studied herein to R. tiomanicus.

\section{Species identification}

As has been reported since the 1970s, Rattus tiomanicus is still the dominant species in mature OPPs in Southeast Asia; however, it has progressively been replaced by Rattus tanezumi (previously Rattus rattus diardii) in several localities, notably the Malaysian peninsula (Wood and Fee 2003). The R. tiomanicus predominance in our study area was confirmed through our trapping experiments. The specimens successfully sequenced herein $(n=110)$ 
were confirmed as $R$. tiomanicus. Additional investigations at the same estate confirmed that $R$. tiomanicus was predominant; the 19 specimens identified using the same molecular barcoding method were $R$. tiomanicus (Andru et al. 2013). Therefore, although we cannot completely exclude sibling species (Wilson and Reeder 2005, Pagès et al. 2010), we can assume that virtually all of the 161 specimens were $R$. tiomanicus.

\section{Predictive modelling, a compromise between parsimony, accuracy, and practicability}

Except for the upper and lower molar row length (CLM1-3 and L5), the monovariate correlations $(r \geq 0.80)$ between the jaw or skull variables and ELW were strong; length of rostrum (LR) and L2 yielded the best correlations (both $\mathrm{r}=0.89$ ). We could not find similar investigations on Rattus species in the international literature, which precludes a comparison. Our results differ from the Microtus results. Shi et al. (2006) found that the length of the Microtus ilaeus Thomas upper molar row correlated best with age, and Quéré et al. (1994) found that the Microtus arvalis Pallas great skull length, LR, and molar row length (CLM1-3) correlated best with age. Moreover, the breadth of palate yielded one of the lowest correlations for $M$. arvalis, whereas in our results, it correlated well with ELW and was included in the final equation. We found a high measurement error for certain variables, such as CLM1-3 (26.9\%), which may be due to the difficulty in finding precise landmarks on bones; therefore, these measurements were discarded from "practical" modelling.

We did not detect a significant difference in ELW between males and females. These data are consistent with Williams (1976) and Shrestha et al. (2002), who did not detect a difference in ELW based on sex for other Rattus species, such as Rattus exulans Peale and Rattus brunneus Hodgs, respectively. The latter species is currently regarded as a Rattus tanezumi synonym (Wilson and Reeder 2005). Certain authors have reported that males have slightly heavier lenses than females, such as for Rattus norvegicus Berkenhout (Hardy et al. 1983) and other rodents (Rowe et al. 1985, Yabe and Arakawa 2009). Our results indicate that the models perform only slightly better when the variable sex is used as a covariate. Therefore, using models 1-3 to predict age may produce a minor sex-related bias. However, Hardy et al. (1983) noted that considering the sex variable in modelling may not be justified because the improvement therefrom is slight.

Many studies aimed at estimating the age, size, or body mass of prey from pellets prefer only lower jaw variables because this organ is highly frequent and well preserved in macroremains (Morris 1979, Trejo and Guthmann 2003, Granjon and Traoré 2007, Bueno and Motta-Junior 2008). However, we found that approximately $70 \%$ of pellets were headless. This result is consistent with other reports (Medway and Yong 1970 in Lenton 1984, Lim et al. 1993, Hafidzi and Naim 2003, Puan et al. 2011). Considering the frequent absence of heads in barn owl pellets on OPPs, we focused on elements other than the skull, jaw, and teeth for modelling. In addition, the tendency of the barn owl to decapitate larger prey may yield a bias if the skull or jaw is used to estimate the age or size distribution and further assess the impact of barn owl predation (Lim et al. 1993). The femur was a good candidate for ELW prediction because it was well represented in our pellet sample, and the variable short femur highly correlated with the ELW. Moreover, the femur measurement error was the lowest compared with the other variables used in the final equations. Thus, the final equation with only the short femur would be more accurate, even if the prediction precision was not greatly improved by considering all the variables.

\section{Model limits and extrapolation}

Age prediction is more accurate in younger animals (Tanikawa 1993, Shrestha et al. 2002). William (1976) found that the ELW was only a useful indicator of Rattus exulans age for up to 3 or 4 months. Myers et al. (1977, in Hardy et al. 1983) studied indigenous rats in Australia and found a similar lack of precision at this threshold, which clearly limits age determination using the ELW.

Our measurements are consistent with the maximum weight of adult rats reported in the literature (Corbett and Hill 1992, Aplin et al. 2003). However, according to Wood (1984), young rats up to approximately $10 \mathrm{~g}$ cannot be trapped by the cage traps used in our study. As the body weight of our specimens ranged from 14 to $139 \mathrm{~g}$, we may not have included certain juvenile individuals in our models.

Because the rats' food supply does not vary greatly month to month owing to a relatively constant temperature and continuous oil palm fruiting throughout the year (Lenton 1984), an effect from rat nutritional status or season on ELW and, thus, age estimations is unlikely.

The equations proposed here are theoretically only applicable for comparing the population structure in the same area during the same period (Quéré et al. 1994). However, even if the rats were trapped in May, extrapolating to another season or year should not be a problem in the tropics and specifically in OPPs without 
chemical control. Indeed, the rat population dynamics do not change markedly with the seasons (due to continuous oil palm tree fruiting; Lenton 1984), the population demography fluctuates slowly, and the weight spectrum is approximately constant (Wood 1984, Wood and Liau 1984b). In contrast, the location is important because population-based genetic variations cannot be excluded.

Owing to the lack of skulls or presence of broken skulls, it is difficult to identify prey species in pellets, which may be an issue for attributing the femur to the correct species. However, the barn owl diet generally reflects the abundance of prey species in the hunting territories (Bunn et al. 1982, Figueroa et al. 2009), as demonstrated for OPPs by Lenton (1984) and Puan et al. (2011). Therefore, because Rattus tiomanicus is the predominant species in our study area, we confidently assume that this species is the major, if not the only, prey in the barn owl pellets studied. In areas where several rat species are sympatric and abundant, new-generation molecular methods can be used to ensure that femurs from the pellets are from R. tiomanicus (Galan et al. 2012).

\section{References}

Andru, J., J.F. Cosson, J.P. Caliman and E. Benoit. 2013. Coumatetralyl resistance of Rattus tanezumi infesting oil palm plantations in Indonesia. Ecotoxicology 22: 377-396.

Aplin, K.P., P.B. Brown, J. Jacob, C.J. Krebs and G.R. Singleton. 2003. Field methods for rodent studies in Asia and the Indo-Pacific. Australian Centre for International Agricultural Research, Canberra. pp. 223.

Augusteyn, R.C. 2008. Growth of the lens: in vitro observations. Clin. Exp. Optom. 91: 226-239.

Bailey, R.C. and J. Byrnes. 1990. A new, old method for assessing measurement error in both univariate and multivariate morphometric studies. Syst. Zool. 39: 124-130.

Barnett, A. and J. Dutton. 1995. Expedition field techniques: small mammals (excluding bats). Royal Geographical Society, London. pp. 131.

Bonnaud, E., E. Vidal, D. Zarzoso-Lacoste and F. Torre. 2008. Measuring rodent incisors from scats can increase accuracy of predator diet studies: an illustration based on island cats and rats. C. R. Biol. 331: 686-691.

Buckle, A.P., T.H. Chia, M.G.P. Fenn and M. Visvalingam. 1997. Ranging behaviour and habitat utilisation of the Malayan wood rat (Rattus tiomanicus) in an oil palm plantation in Johore, Malaysia. Crop Prot. 16: 467-473.

Bueno, A.d.A. and J.C. Motta-Junior. 2008. Small mammal prey selection by two owl species in southeastern Brazil. J. Raptor Res. 42: 248-255.

Bunn, D.S., A.B. Warburton and R.D.S. Wilson. 1982. The barn owl. T.\&A.D. Poyser, London. pp. 264.

\section{Conclusion}

Our study demonstrates that the femur length is relevant to ELW predictions for prey from macroremains, specifically in OPPs, wherein most pellets are headless. Our models represent a preliminary step to establish a relative age structure for Rattus tiomanicus consumed by the barn owl and to compare it to the population structure in the field, with a view to further assessing the impact of barn owl predation and improving ecologically based pest control.

Acknowledgments: We thank the technicians from SMARTRI who helped with the fieldwork as well as PTSmart Tbk for their accommodation and for providing access to the facilities and plantation. We are grateful to the State Ministry of Research and Technology of Indonesia, which supported this research (0131/SIP:FRP/ $\mathrm{SM} / \mathrm{V} / 2011)$.

Received July 18, 2013; accepted January 30, 2014; previously published online March 5, 2014

Burlet, P., P. Deplazes and D. Hegglin. 2010. Efficient age determination: how freezing affects eye lens weight of the small rodent species Arvicola terrestris. Eur. J. Wildl. Res. 56: 685-688.

Burnham, K.P. and D.R. Anderson. 2002. Model selection and multi-model inference: a practical information - theoretic approach (2nd edition). Springer-Verlag, New York. pp. 488.

Chia, T.H. 2005. Rat control in oil palm plantations: a review. Planter 81: $15-26$.

Chia, T.H., J.L. Lim and A. Buckle. 1995. Barn owls for rat control on oil palm plantations - do they work? Planter 71: 109-117.

Clairon, N., D. Lepicard, D. Dumas, D. Chavernac, G.A. Dehne, S. Piry, F. Dorkeld and Y. Chaval. 2010. Rodent SEA: a web service for rodent species identification in South-East Asia. Available at http://www.ceropath.org/barcoding_tool/rodentsea. Accessed 3 October, 2012.

Claude, J. 2008. Morphometrics with R. Springer, New York. pp. 336.

Corbett, G.B. and J.E. Hill. 1992. The mammals of the Indomalay region: a systematic review. Natural History Museum Publications, Oxford University Press, New York. pp. 488.

Corley, R.H.V. and P.B. Tinker. 2003. The oil palm. 4th edition. Blackwell Sciences Ltd., Oxford. pp. 592.

Dickman, C.R., M. Predavec and A.J. Lynam. 1991. Differential predation of size and sex classes of mice by the barn owl, Tyto alba. Oikos 62: 67-76.

Duckett, J.E. 1976. Owls as major predators of rats in oil palm estates with particular reference to the barn owl (Tyto alba). Planter 52: 4-15. 
Duckett, J.E. 2008. The expansion of range and population of the Barn owl (Tyto alba javanica) in Peninsular Malaysia and in Sumatra and adjacent islands: a review and update on the current situation. Planter 84: 799-807.

Figueroa, R., A. Ricardo, J.R. Rau, S. Mayorga, D.R. Martínez, E.S. Corales, S.A. Mansilla and R. Figueroa M. 2009. Rodent prey of the barn owl Tyto alba and short-eared owl Asio flammeus during winter in agricultural lands in Southern Chile. Wildl. Biol. 15: 129-136.

Friend, M. 1967. A review of research concerning eye lens weight as a criteria of age in animals. N. Y. Fish Game J. 14:152-165.

Galan, M., M. Pagès and J.-F. Cosson. 2012. Next-generation sequencing for rodent barcoding: species identification from fresh, degraded and environmental samples. PLOS ONE 7: e48374. http://dx.doi.org/10.1371/journal.pone.0048374. Accessed 12 November, 2012.

Gliwicz, J. and E. Jancewicz. 2001. Aging and cohort dynamics in Sorex shrews. Acta Theriol. 46: 225-234.

Granjon, L. and M. Traoré. 2007. Prey selection by barn owls in relation to small-mammal community and population structure in a Sahelian agro-ecosystem. J. Trop. Ecol. 23: 199-208.

Hafidzi, M.N. 1994. Natural predation: a viable option for controlling vertebrate pest in Malaysia. Planter 70: 161-172.

Hafidzi, M.N. and M. Naim. 2003. Prey selection by barn owl in rice fields in Malaysia. In: (G.R. Singleton, L. A. Hinds, C.J. Krebs and D.M.D Spratt eds.) Rats, mice and people: rodent biology and management. Australian Center for International Agriculture Research, Canberra. pp. 220-223.

Hafidzi, M.N. and M.K. Saayon. 2001. Status of rat infestation and recent control strategies in oil palm plantations in Peninsular Malaysia. Pertanika J. Trop. Agric. Sci. 24: 109-114.

Hardy, A.R., R.J. Quy and L.W. Huson. 1983. Estimation of age in the Norway rat (Rattus norvegicus Beerkenhout) from the weight of the eye lens. J. Appl. Ecol. 20: 97-102.

Herbreteau V., S. Jittapalapong, W. Rerkamnuaychoke, Y. Chaval, J.-F. Cosson and S. Morand, eds. 2011. Protocols for field and laboratory rodent studies. Retrieved from CERoPath project: http://www.ceropath.org/FichiersComplementaires/ Herbreteau_Rodents_protocols_2011.pdf. Accessed 14 April, 2012.

Jánová, E., J. Nesvadbová and E. Tkadlec. 2007. Is the eye lens method of age estimation reliable in voles? Folia Zool. 56: 119-125.

Kittlein, M.J. 1997. Assessing the impact of owl predation on the growth rate of a rodent prey population. Ecol. Model. 103: 123-134.

Lalis, A., E. Lecompte, R. Cornette, S. Moulin, R.S. Machangu, R. Makundi, V.M. Aniskine and C. Denys. 2006. Polymorphism of the age population structure of two wild Mastomys natalensis (Rodentia: Muridae) Tanzanian habitat samples: a multicriteria comparison. Mammalia 70: 293-299.

Leirs, H. 1994. Population ecology of Mastomys natalensis (Smith, 1984). Implications for rodents control in Africa. Agricultural Edition 35, Belgian Administration for Development Cooperation, Brussels. pp. 268.

Le Louarn, H. 1971. Détermination de l'âge par la pesée du cristallin chez quelques espèces de rongeurs. Mammalia 35: 636-643.

Lenton, G.M. 1980. Biological control of rats in oil palm by owls. In: (J.I. Furtad, ed.) Proceedings of the 5th International Symposium of Tropical Ecology "Tropical Ecology and
Development”, 16-21 April 1979. Kuala Lumpur, Malaysia. pp. 615-621.

Lenton, G.M. 1984. The feeding and breeding ecology of barn owls Tyto alba in Peninsular Malaysia. Ibis 126: 551-575.

Leveau, L.M., P. Teta, R. Bogdaschewski and U.F.J. Pardiñas. 2006. Feeding habits of the barn owl (Tyto alba) along a longitudinallatitudinal gradient in central Argentina. Ornitol. Neotrop. 17: 353-362.

Liau, S.S. 1990. Rat population in oil palm replants and crop loss assessment (Malaysia). 3rd International Conference on Plant Protection in the Tropics, 20-23 Mar 1990. Malaysian Plant Protection Society, Kuala Lumpur. pp. 8-18.

Liau, S.S., C.G. Fee, S.C. Sim and C.T. Ho. 1993. Rat species composition and distribution in West Malaysian plantations (with particular reference to oil palm plantations). In: (Y. Basiron, S. Jalani, K.C. Chang, S.C. Cheah, I. E Henson, N. Kamarudin, K. Paranjothy, N. Rajanaidu, D. Tayeb and D. Ariffin, eds.) Proceedings of the 1991 PORIM International Palm Oil Conference - Progress, Prospects \& Challenges Towards the 21st Century, Module I Agriculture. 9-14 September 1991. Palm Oil Research Institute of Malaysia, Kuala Lumpur. pp. 511-516.

Lim, J.L., M.G.P. Fenn, A.P. Buckle, M. Visvalingam and J.K. Ward. 1991. Prey selection by barn owls (Tyto alba) and its impact on rat control in oil palm plantations. In: (Y. Basiron, S. Jalani, K.C. Chang, S.C. Cheah, I.E. Henson, N. Kamarudin, K. Paranjothy, N. Rajanaidu, D. Tayeb and D. Ariffin, eds.) Proceedings of the 1991 PORIM International Palm Oil Conference - Progress, Prospects \& Challenges Towards the 21st Century, Module I Agriculture. 9-14 September 1991. Palm Oil Research Institute of Malaysia, Kuala Lumpur. pp. 458-465.

Lim, J.L., M. Visvalingam, A.P. Buckle, J.K. Ward and M.G.P. Fenn. 1993. Prey selection by Barn Owls (Tyto alba) in an oil palm plantation in Malaysia. J. Plant Prot. 10: 185-192.

Lord, R.D. 1959. The lens as an indicator of age in cotton-tail rabbits. J. Wildl. Manage. 23: 358-360.

Medway, L. and G.C. Yong. 1970. Barn owl pellets from Kulai, Johore. Malay. Nat. J. 23: 171-172.

Morris, P. 1972. A review of mammalian age determination methods. Mammal Rev. 2: 69-104.

Morris, P. 1979. Rats in the diet of the Barn owl (Tyto alba). J. Zool. 189: 540-545.

Myers, K., J. Carstairs and N. Gilbert. 1977. Determination of age of indigenous rats in Australia. J. Wildl. Manage. 41: 322-326.

Oil World. 2012. Oil World annual 2012. Oil World, Hamburg.

Pagès, M., Y. Chaval, V. Herbreteau, S. Waengsothorn, J.F. Cosson, J.P. Hugot, S. Morand and J. Michaux. 2010. Revisiting the taxonomy of the Rattini tribe: a phylogenybased delimitation of species boundaries. BMC Evol. Biol. 10: 1-27.

Poulet, A.R. 1980. Détermination de l'âge par la pesée des cristallins chez cinq espèces de rongeurs Muridés et Gerbillidés de l'ouest de l'Afrique. Mammalia 44: 381-398.

Puan, C.L., A.W. Goldizen, M. Zakaria, M.N. Hafidzi and G.S. Baxter. 2011. Absence of differential predation on rats by Malaysian barn owls in oil palm plantations. J. Raptor Res. 45: 71-78.

Pucek, Z. and V.P.W. Lowe. 1975. Age criteria in small mammals. In: (F.B. Golley, K. Petrusewicz and L. Ryskowski, eds.) Small mammals: their productivity and population dynamics. Cambridge University Press, Cambridge. pp. 55-72. 
Quéré, J.-P., P. Giraudoux, P. Delattre and B. Faivre. 1994. Détermination de la structure en âge relatif d'une population de Microtus arvalis (Rongeurs, Arvicolidés) par mesures ostéométriques crâniennes ou mandibulaires. Mammalia 58: 269-282.

Rowe, F.P., A. Bradfield, R.J. Quy and T. Swinney. 1985. Relationship between eye lens weight and age in the wild house mouse (Mus muculus). J. Appl. Ecol. 22: 55-61.

Saint Girons, M.-C. 1973. L'âge des micromammifères dans le régime de deux rapaces nocturnes, Tyto alba et Asio otus. Mammalia 37: 439-456.

Sherfy, M.H., T.A. Mollett, K.R. McGowan and S.L. Daugherty. 2006. A reexamination of age-related variation in body weight and morphometry of Maryland Nutria. J. Wildl. Manag. 70: $1132-1141$.

Shi, L., R.-X. Zai, X.-Y. Ma and Y.-H. Zhou. 2006. Studies on age and reproduction of Tianshan vole (Microtus ilaeus). Xinjiang Agricultural Sciences 43: 498-502.

Shrestha, P.D.D., T. Yabe and T. Kusano. 2002. Eye-lens weight curve for estimation of age in rats, Rattus rattus brunneus and Bandicota bengalensis in Nepal. Mamm. Study 27: 87-89.

Small, C.M. 1990. Research on the use of barn owls Tyto alba for biological control of rats in oil palm plantations: 1986-1989. In: (S. Jalani, Z.Z. Zin, K. Paranjothy, D. Ariffin, N. Rajanaidu, S.C. Cheah, M.W. Basri and I. E Henson, eds.) Proceedings of the 1989 PORIM International Palm Oil Conference. 5-9 September 1989. Palm Oil Research Institute of Malaysia, Kuala Lumpur. pp. 342-356.

Tanikawa, T. 1993. An eye-lens weight curve for determining age in black rats, Rattus rattus. J. Mammal. Soc. Jpn. 18: 49-51.
Trejo, A. and N. Guthmann. 2003. Owl selection on size and sex classes of rodents: activity and microhabitat use of prey. J. Mammal. 84: 652-658.

Turner, P.D. and R.A. Gillbanks. 2003. Oil palm cultivation and management. The Incorporated Society of Planters, Kuala Lumpur. pp. 915.

Williams, J.M. 1976. Determination of age of Polynesian rats. Proc. New Zeal. Ecol. Soc. 23: 79-82.

Wilson, D.E. and D.M. Reeder, eds. 2005. Mammals species of the world. A taxonomic and geographic reference (3rd edition). Johns Hopkins University Press, Baltimore. pp. 142.

Wood, B.J. 1984. A long-term study of Rattus tiomanicus populations in an oil palm plantation in Johore, Malaysia: I. Study methods and population size without control. J. Appl. Ecol. 21: 445-464.

Wood, B.J. and C.G. Fee. 2003. A critical review of the development of rat control in Malaysian agriculture since the 1960s. Crop Prot. 22: 445-461.

Wood, B.J. and S.S. Liau. 1984a. A long-term study of Rattus tiomanicus populations in an oil palm plantation in Johore, Malaysia: II. Recovery from control and economic aspects. J. Appl. Ecol. 21: 465-472.

Wood, B.J. and S.S. Liau. 1984b. A long-term study of Rattus tiomanicus populations in an oil palm plantation in Johore, Malaysia: III. Bionomics and natural regulation. J. Appl. Ecol. 21: 473-495.

Yabe, T. and O. Arakawa. 2009. Eye-lens weight curve for estimation of age in the Japanese grass vole, Microtus montebelli Milne-Edwards (Rodentia: Muridae). Appl. Entomol. Zool. 44: 501-504.

Yezeriniac, M.S., S.C. Lougheed and P. Handford. 1992. Measurements errors and morphometric studies: statistical power and observer experience. Syst. Biol. 41: 471-482. 